\title{
Aprendizagem e formação docente: uma analítica da ordem do discurso do Prolnfantil
}

\author{
Rodrigo Saballa de Carvalho \\ Universidade Federal da Fronteira Sul
}

\section{Resumo}

0 artigo problematiza os discursos sobre aprendizagem e formação docente presentes no material do Programa de Formação Inicial para Professores em Exercício na Educação Infantil (Prolnfantil), ocorrido no período de 2005 a 2012. Trata-se de um curso na modalidade normal, em nível de ensino médio, à distância, do Ministério da Educação, que objetiva a formação de professores que atuam na educação infantil e não possuem titulação. A metodologia de pesquisa utilizada é a análise do discurso. A partir desse estudo, conclui-se que os discursos do Prolnfantil operam no governamento do professor, prescrevendo metodologias de como ele deve atuar e se reconhecer enquanto profissional.

Palavras-chave: Prolnfantil. Discurso. Aprendizagem. Formação docente. 


\section{Learning and teacher training: an analysis of the order of discourse in Prolnfantil}

The article discusses the discourses on learning and teacher training present in the materials for the Program of Initial Training for Teachers Working in Early Childhood Education (Prolnfantil), which took place from 2005 to 2012. This is a technical distance education course, at a high school level, under the Ministry of Education, which aims to train teachers working in early childhood education who do not have the required diploma. The methodology of research used was discourse analysis. Based on this study, the conclusion is that Prolnfantil's discourses operate by governing teachers, prescribing methodologies for how they must act and recognize themselves as professionals.

Keywords: Prolnfantil. Discourse. Learning. Teacher training.

\section{Aprendizaje y formación docente: una analítica de la orden del discurso del Prolnfantil}

El artículo problematiza los discursos acerca del aprendizaje y de la formación docente presentes en el material del Programa de Formación Inicial del Profesorado en Ejercicio en la Educación Infantil (Prolnfantil), ocurrido en el período de 2005 a 2012. Este es un curso de nivel secundario, a distancia, del Ministerio de Educación (MEC), cuyo objetivo es formar profesores que trabajan en la Educación Infantil y no tienen titulación. La metodología utilizada es el análisis del discurso. A partir de este estudio, se concluye que el discurso del Prolnfantil opera en la gobernanza del profesor, prescribiendo metodologías de como este debe actuar y reconocerse en cuanto profesional.

Palabras clave: Prolnfantil. Discurso. Aprendizaje. Formación Docente. 


\section{Considerações iniciais}

Este artigo é decorrente de uma pesquisa que, a partir das contribuições dos estudos desenvolvidos por Michel Foucault, teve como foco de análise a problematização dos discursos sobre aprendizagem e formação docente presentes no material do Programa de Formação Inicial para Professores em Exercício na Educação Infantil (Prolnfantil). 0 objetivo do artigo é problematizar as estratégias discursivas presentes nos materiais analisados, destacando os regimes de verdade que caracterizam a ordem do discurso do Prolnfantil enquanto uma arena cultural - um palco de operacionalidade do poder. Dessa forma, serão discutidos os modos como tais materiais, enquanto artefatos culturais, investidos de prescrições e regulações morais, operam no governamento da prática pedagógica na educação infantil, ensinando o professor a conduzir sua vida e a vida das crianças.

O Prolnfantil é um curso na modalidade normal, em nível de ensino médio, à distância, para a formação de professores que atuam na educação infantil e não possuem a formação mínima exigida pela Lei de Diretrizes e Bases da Educação Nacional (LDB - Lei no 9.394/96). Ele é um programa de caráter emergencial promovido pelo Ministério da Educação em parceria com os estados e municípios brasileiros interessados. Seu período de vigência foi de 2005 a 2012, sendo que atualmente se encontra em processo de avaliação para que novas edições sejam ofertadas.

A duração do curso do Prolnfantil é de dois anos, perfazendo um total de 3.392 horas, distribuídas em quatro módulos semestrais de 848 horas cada um. Conforme a diretriz nacional do programa, o professor, para ser matriculado, deve ter idade mínima de 18 anos, estar atuando há pelo menos seis meses como docente e comprometer-se a permanecer vinculado a uma instituição de educação infantil durante os dois anos do curso.

Os objetivos da proposta, conforme consta no Guia Geral do Programa (2005), são: al habilitar em magistério para a educação infantil os professores em exercício; b) elevar o nível de conhecimento e aprimorar a prática pedagógica docente; c) valorizar o magistério, oferecendo condições de crescimento profissional e pessoal do professor; e d) contribuir para a qualidade social da educação das crianças que se encontram na educação infantil.

0 currículo do curso está organizado em áreas temáticas que congregam a Base Nacional Comum do Ensino Médio e a Formação Pedagógica. A primeira contempla as disciplinas de: a) linguagens e códigos; b) identidade, sociedade e cultura; c) matemática e lógica; e d) vida e natureza. Por sua vez, a segunda é constituída pelas disciplinas de: al fundamentos da educação; b) organização do trabalho pedagógico; e c) língua estrangeira moderna. 
Conforme Barbosa (2001), para operacionalizar o currículo previsto, o curso conta com material didático específico para a educação à distância e com acompanhamento sistemático do professor cursista, realizado pela equipe de tutoria. Através do acompanhamento, o professor pode obter informações para a qualificação de sua prática, socializar suas experiências e esclarecer suas dúvidas.

0 trabalho formativo desenvolvido durante o curso é divido em quatro módulos semestrais: 1. História, legislação e política educacional; 2. A criança e suas interações; 3. Proposta pedagógica: conceitos, elementos constitutivos e mediadores; e 4. Pressupostos teóricos metodológicos do trabalho docente. Os módulos contemplam os componentes curriculares da Base Nacional Comum do Ensino Médio e os respectivos componentes da Formação Pedagógica.

A proposta do material do curso objetiva capacitar o docente em relação ao domínio dos processos necessários para o desempenho da ação pedagógica. Isso ocorre por meio de metodologias e estratégias, que configuram uma espécie de "liberdade regulada" do cursista. A liberdade regulada apresentada pelos materiais utilizados na formação de professores à distância, conforme Bocchetti (2008, p. 74), "permite um jogo recorrente entre autonomia e sujeição à norma, essencial na produção de um discurso crítico que mescla clamores ao questionamento e à inquietação com uma necessidade naturalizada de sujeição à norma".

Em outras palavras, pode-se dizer que o material de estudo possibilita que o professor se sinta autônomo em relação ao desenvolvimento de suas práticas, pois são recorrentes as orientações que convocam o cursista a avaliar a sua prática em sala de aula e a fazer suas próprias escolhas para a qualificação de seu trabalho. Porém, não é ressaltado que tais escolhas se encontram sempre limitadas às lições que compõem a ordem do discurso do programa.

Após essa exposição realizada sobre o Prolnfantil, na próxima seção serão discutidos os aspectos metodológicos da pesquisa.

\section{Metodologia, questões de pesquisa e ferramentas analíticas}

A partir do referencial teórico foucaultiano, será desenvolvida uma análise do discurso do material didático do Prolnfantil. Ele é entendido como um discurso pedagógico que, no âmbito da formação de professores de educação infantil, opera articulando jogos de poder e vontades de saber, estabelecendo vínculos entre proposições e prescrevendo uma série de ações que tem como objetivo a produção de crianças e docentes de determinado tipo.

0 corpus de análise da pesquisa é constituído pelo Guia Geral do Programa e 
por livros de estudo (Módulo IV: unidades 4 a 8) utilizados pelos professores no decorrer do curso. 0 Módulo IV foi escolhido para análise pelo fato de abordar especificamente os pressupostos teórico-metodológicos do trabalho docente nos componentes curriculares de linguagem, artes, matemática, natureza e sociedade.

Devido aos limites deste artigo, não será apresentado nem discutido o contexto de produção dos materiais analisados. Assim, as análises serão desenvolvidas a partir das seguintes questões: al “Que estratégias discursivas são utilizadas para orientar a conduta dos professores em relação à ação pedagógica na educação infantil?"; b) "De que modos os discursos emergentes do Guia Geral e dos livros de estudos do Prolnfantil promovem um determinado modo de significar a aprendizagem na educação infantil e a formação docente para esta etapa de ensino?"

Éimportante destacar que os conceitos foucaultianos de discurso e governamento serão utilizados enquanto ferramentas analíticas. Nessa perspectiva, o discurso será considerado um produtor de verdades e um dispositivo estratégico de relações de poder. Os discursos serão vistos como práticas organizadoras da realidade, que estabelecem hierarquias e distinções, articulando o dizível e o visível. Conforme Foucault (1987, p. 56), os discursos são "práticas que formam sistematicamente os objetos de que falam". Pode-se então depreender que os discursos sobre aprendizagem e formação docente presentes no material didático do Prolnfantil são práticas discursivas.

Em uma perspectiva foucaultiana, o discurso é conceituado como um conjunto de enunciados que se apoia na mesma formação discursiva. 0 discurso, segundo Foucault (2007, p. 132), “não é uma forma ideal e intemporal que teria, além do mais, uma história”, pois para o filósofo o problema não consiste em saber como e por que o discurso pode emergir e tomar corpo em determinado ponto do tempo. Por essa razão, os discursos produzidos no âmbito social são vistos como práticas organizadoras da realidade.

Esse entendimento possibilita afirmar que os discursos formam sistematicamente os sujeitos e os objetos dos quais tratam, já que estão inscritos em formas regulamentadas de poder e sujeitos a múltiplas coerções. Os discursos não são tomados por uma via interpretativa, ou seja, não se procura um suposto sentido que estaria subjacente a eles, já que a verdade é entendida como uma produção do poder. A verdade é o que permite ao poder funcionar mediante determinados discursos.

Essa noção de discurso rompe com os sentidos comumente utilizados na linguística e nas análises fenomenológicas, nas quais se destaca uma dicotomia entre os fenômenos da língua social e da fala individual, uma vez que o discurso é 
entendido por tais campos apenas como realização da fala de um sujeito produtor de significados. Essas perspectivas procuram deduzir do discurso algo que se refere ao sujeito falante, buscando reencontrar suas intencionalidades. Na contramão dessas análises, na perspectiva foucaultiana, os discursos têm uma condição própria, a qual não exige a interpretação do que é dito, mas a especificação das condições de existência dos enunciados.

Corroborando os argumentos expostos, Palamidessi (1996), em suas análises a respeito da produção do professor construtivista nos discursos curriculares, afirma que:

[...] o discurso é uma prática modelizadora da realidade, hierarquizadora e articuladora de relações específicas entre o visível e o dizível. Não é o reflexo puro de uma realidade exterior que a determinaria mecanicamente; é, a partir de tal perspectiva, uma categoria constituída e constituinte. Constituída, porque é uma prática mediadora de práticas não discursivas; constituinte, porque o discurso é a instância, o espaço que torna possível a construção e emergência de significações e sentidos. (Palamidessi, 1996, p. 193)

Reitera-se aqui o fato de que não se procura um significado que estaria subjacente à própria materialidade dos discursos. Os discursos têm sentido somente a partir de sua exterioridade, e não a partir da lógica interna de seus enunciados. Não se tem a pretensão de tentar extrair dos textos o que exatamente os sujeitos dos discursos queriam dizer, mas a intenção de procurar estabelecer sempre a relação entre os enunciados e aquilo que eles descrevem. Interroga-se a linguagem, o que efetivamente foi le él dito a respeito de determinado aspecto, sem a intencionalidade de fazer interpretações reveladoras que supostamente contribuíram para "conscientizar" os indivíduos.

Por isso, Foucault (2005, p. 53) alerta para não transformarmos “o discurso em um jogo de significações prévias; não imaginarmos que o mundo nos apresenta uma face legível que teríamos que apenas decifrar", pois ele não é cúmplice de nosso conhecimento. Em tal perspectiva, o indivíduo não constrói sentidos e significados de maneira livre, mas através (e por meio) de uma série de sistemas de restrições e incitações discursivas que constituem determinada ordem. Essa ordem atravessa o indivíduo, localiza-o em uma posição e limita os conteúdos de suas mensagens.

Como pode ser percebido, o foco das problematizações não é o significado das palavras, mas o funcionamento e a produtividade dos discursos nas práticas sociais, ordenando espaços, fixando tempos e inventando subjetividades de docentes e crianças. Considerando que não exista nada por trás dos textos, abre-se a possibilidade de investigar quais são as condições de existência de determinado 
enunciado ou de um conjunto de enunciados. É possível então problematizar os discursos sobre aprendizagem e formação docente presentes no material didático do Prolnfantil e o governamento operado pelo curso, que acaba por inventar professores e crianças de determinado tipo.

Cabe esclarecer que o conceito de governamento é entendido como conduta da conduta, ou seja, como qualquer modo mais ou menos calculado de direcionamento dos comportamentos ou ações. Foucault (2008) destaca que a conduta é a atividade que consiste em conduzir, mas é também a maneira como uma pessoa se conduz, como se deixa conduzir, como é conduzida e também como se comporta sob o efeito de uma conduta que seria ato de condução.

Nesse sentido, o termo conduta, além de se referir aos comportamentos e às ações, relaciona-se às noções morais de autogestão e autorregulação. Tais noções morais não operam somente de acordo com os interesses das pessoas, pois muitas vezes estão envolvidas diretamente com as relações pelas quais elas são capturadas e produzidas. É este o caso dos livros em análise, que operam no governamento de professores em formação, como poderá ser observado nos trechos a seguir.

0 curso se propõe a contribuir para a formação de: um professor capaz de dar continuidade a seu próprio processo de aprendizagem, um cidadão responsável e participativo, integrado ao projeto da sociedade em que vive e, ao mesmo tempo, crítico e transformador. (Brasil, 2005, p. 26)

No Prolnfantil, a educação é entendida como um processo permanente que acontece dentro e fora da escola, articulando conhecimentos formalmente estruturados e saberes adquiridos com a prática. Além disso, enfatiza o caráter histórico e cultural do conhecimento, possibilitando uma formação articulada com as necessidades sociais e promovendo a autorrealização e o desenvolvimento dos profissionais envolvidos. (Brasil, 2005, p. 26)

A prática pedagógica funciona como o ponto de partida para a teoria e também se reformula a partir dela. Supõe a análise e a tomada de decisões em processo, beneficiando-se do trabalho coletivo e da gestão democrática. A capacidade de tematizar a própria prática como atividade inerente ao professor reflexivo é fonte de ação que institui e transforma. (Brasil, 2005, p. 30)

Nesses trechos, o governamento operacionaliza-se a partir da tentativa deliberada de conduzir aspectos dos comportamentos dos indivíduos. No caso dos livros em análise, o professor em formação é interpelado a assumir o papel de agente de mudança, de agente que é "capaz de lidar com o próprio processo permanente de aprendizagem", de "tematizar a prática docente", de "articular 
saberes teóricos e práticos" e de, sobretudo, qualificar a docência na educação infantil a partir da operacionalização das lições aprendidas no decorrer do curso. 0 governamento em questão caracteriza-se pela unificação de estratégias produtivas que têm o intuito de atingir fins políticos, conduzindo a todos e a cada um, através de um processo que, ao mesmo tempo, individualiza, totaliza e normaliza.

Veiga-Neto (2000, p. 186) corrobora tais argumentos ao afirmar, entre outros aspectos, que o bom governamento é aquele que governa de modo econômico, “procurando obter maiores resultados com mínimo esforço tanto no que se refere às questões monetárias e financeiras como também em relação ao tempo, aos afetos, ao prazer e à felicidade". Em suma, o governamento depende do conhecimento e da produção de verdades que personificam o que será governado, tornando tal prática pensável e calculável. Isso pode ser percebido no esclarecimento sobre o currículo do programa, a ser transcrito a seguir.

Nesse sentido, o currículo do Prolnfantil: a) respeita e valoriza as características culturais do Professor Cursista como sujeito histórico, que tem um passado e que pertence a um grupo social com experiências culturais próprias que definem seus interesses e suas necessidades de aprendizagem; b) utiliza práticas de aprendizagem que não se configuram apenas como autoaprendizagem, mas também como interaprendizagem, quebrando o isolamento profissional em que se encontra grande parte dos professores; c) vale-se da modalidade de ensino a distância, na qual se conjugam atividades presenciais e a distância, mobilizando todos os recursos para atingir diretamente 0 cursista, sensibilizando-o, despertando seu interesse e garantindo a qualidade das aprendizagens realizadas. (Brasil, 2005, p. 28)

O governamento é considerado um produtivo conjunto de práticas estratégicas e abertas que indica as formas por meio das quais se podem conduzir as condutas de si e dos outros, através de um jogo ininterrupto - que seduz e regula, suscitando apetites e desejos. Por esse motivo, no artigo, serão discutidos os modos como os livros analisados, investidos de conselhos e regulações morais, operam no governamento dos professores cursistas. Assim, eles os ensinam a conduzir suas vidas, a conduzir a vida das crianças, a se relacionar consigo mesmo e com os outros, em nome de certas verdades.

No intuito de visibilizar as estratégias discursivas presentes nas obras, a discussão analítica ocorrerá a partir de três unidades. Inicialmente, será realizada a cartografia de algumas estratégias de persuasão presentes na retórica utilizada nos textos dos livros. Em seguida, serão analisados os discursos sobre aprendizagem infantil presentes no material. Por fim, será abordada a análise dos discursos sobre formação docente, enfatizando os modos como são posicionados os professores a partir da definição de determinado perfil profissional. 


\section{Prolnfantil: cartografando (algumas) estratégias de persuasão dos livros}

0 programa vale-se dos benefícios da formação em serviço, que torna possível a reflexão teórica sobre a prática do professor cursista, considerando as características, as necessidades, os limites e as facilidades apresentados pela instituição em que atua. Dessa forma, a própria instituição de educação infantil torna-se o lugar privilegiado de formação do professor, com efeitos significativos sobre a sua prática pedagógica. (Brasil, 2005, p. 15)

A construção da identidade profissional constitui um dos eixos verticais do currículo. Coordenando os eixos integradores dos módulos e buscando dar organicidade ao curso como um todo, estrutura-os em um contínuo que parte das relações entre a realidade social e a educação, sendo mediado pela dinâmica da instituição que dimensiona o trabalho com as crianças e oferece condições para a compreensão da especificidade profissional do professor. (Brasil, 2005, p. 33)

Na leitura dos trechos, é possível visualizar uma série de palavras de ordem, como: benefícios da formação em serviço, reflexão teórica sobre a prática, instituição de educação infantil como espaço privilegiado de formação do professor, aprendizagem como desenvolvimento de competências, identidade profissional, relações entre identidade social e educação. Tais palavras de ordem constituem o vocabulário utilizado pelos autores para prescrever em suas obras um modelo ideal de formação do professor de educação infantil.

Esse vocabulário, através de seu caráter instrumental, opera de modo sutil no governamento dos professores cursistas, enfatizando um modelo-padrão de educação e produzindo determinada subjetividade, ou seja, um docente empreendedor de si mesmo. A partir do início do curso, a solução para a mudança na prática da sala de aula está exclusivamente nas mãos do professor - cabe a ele operacionalizar em sala de aula os conhecimentos que estão sendo aprendidos. Sibilia (2012) afirma que essa retórica empreendedora atualmente já não se restringe somente aos cenários do mundo empresarial, mas também se faz presente em discursos que responsabilizam o indivíduo por administrar os seus conhecimentos e por ser protagonista das mudanças sociais.

No âmbito da produção dessa subjetividade empreendedora, é possível perceber que a palavra-chave é a reflexão sobre a própria prática, pois é através do programa que (supostamente) o docente desenvolve competências teóricas e práticas para atuar em sala de aula. Para tanto, é preciso que o professor cursista observe criticamente o trabalho que desenvolve e modifique constantemente a sua prática a partir dos aprendizados decorrentes das leituras, procurando atingir 
o perfil profissional requerido pelo programa.

A formação do professor é utilizada como uma estratégia de governamento para que o leitor cursista, ao desejar ser o educador exitoso proposto pelas publicações, operacionalize na educação das crianças as prescrições descritas. Procurando se aproximar do leitor, os autores reiteradamente apresentam, nos livros, exemplos de práticas desenvolvidas no cotidiano da educação infantil, procurando conduzir o leitor em suas análises, como poderá ser observado a seguir.

No dia seguinte, as crianças chegaram eufóricas com a vitória do Brasil e ansiosas para escrever a notícia. Sentadas no chão, juntamente com a professora, num dos cantos da sala, foram conversando sobre as informações colhidas sobre o jogo. A professora, atuando como escriba, propôs que se sentassem nas cadeirinhas, em meia-lua, em frente ao quadro, para que ela pudesse ir registrando no cartaz. E assim ia fazendo as perguntas que induziam à elaboração da notícia: 0 que aconteceu? Quando? Onde? Como? Quem? As crianças respondiam e ela as desafiava em relação à estrutura das frases que deveriam ser escritas. 0 resultado foi um texto de notícia bem estruturado, real, tal como poderia ser encontrado no mundo adulto, em um jornal de verdade. A escolha da manchete da notícia gerou grande discussão, uma vez que a professora disse que a manchete tem que provocar o leitor. 0 título construído pelo grupo com a intervenção da professora foi: Alegria dos torcedores do Brasil. (Lopes; Mendes; Faria, 2006c, p. 61-62)

O exemplo citado no material "captura”, “seduz" e "mobiliza” o professor através de seu vocabulário, linguagem e prática específicas, mostrando sempre que ele é livre para fazer suas escolhas, mas que, se optar pelo modelo proposto, o seu sucesso como docente será garantido. Percebe-se, nas práticas exemplificadas nos livros, uma infinidade de técnicas e estratégias que sugerem o que os professores devem ser, como devem atuar e que tipos de sujeito devem se tornar: esclarecidos, empreendedores, inovadores e cognitivistas.

Bocchetti e Bueno (2012) apontam que o caráter autoinstrucional dos materiais utilizados em formação de professores à distância está associado a um processo de autorregulação permanente do leitor cursista. Tal colocação evidencia que são postas em funcionamento práticas de governamento nos discursos das obras, fazendo que o leitor se relacione com as verdades propostas, se identifique com determinado estilo de educação e seja incitado e mobilizado a assumir a posição de educador que atua através da reflexão constante sobre a sua prática. Isso poderá ser acompanhado nos excertos a seguir.

Já que estamos conversando sobre as linguagens visuais e as possibilidades expressivas 
das crianças, que tal você listar, para depois debater em seu grupo, o que você costuma propor em termos do trabalho com artes visuais aos meninos e meninas com os quais trabalha? Ao construir esta lista, é importante pensar: tenho proporcionado às crianças a expressão em linguagens variadas ou há uma delas que tem predominado? As atividades propostas estão ressaltando o caráter autoral das produções das crianças ou baseiam-se, privilegiadamente, na cópia e na reprodução? (Lopes; Mendes; Faria, 2006b, p. 35)

Estamos chegando ao final do curso! Você consegue perceber mudanças na sua prática? Como as leituras têm contribuído para a reflexão sobre o seu trabalho? Qual das unidades foi a que mais te envolveu? Escolha uma prática ou reflexão que passou a fazer parte de seu cotidiano a partir do estudo que estamos desenvolvendo. Leve para compartilhar com seu tutor. (Lopes; Mendes; Faria, 2006e, p. 69)

Encerramos esta seção destacando que todas essas propostas de trabalho que apresentamos anteriormente são apenas sugestões para pensarmos em fazer um trabalho criativo com a matemática na educação infantil. Claro que você tem a liberdade de utilizar o que quiser, mas procure sempre considerar as adaptações necessárias à sua turma. Insistimos na ideia de que a experiência é que proporciona ao(à) professorla) melhor percepção das possibilidades de trabalho para cada realidade. (Lopes; Mendes; Faria, 2006e, p. 64-65)

São perceptíveis os modos sutis pelos quais os educadores são mobilizados a seguir os conselhos dos autores. Através de uma profusão de evocativos, os autores, em tom de diálogo, comunicam-se diretamente com os professores, aproximando-se das estratégias persuasivas utilizadas em obras de autoajuda amplamente comercializadas no mundo contemporâneo.

Os educadores são incitados a seguir os conselhos, não por coerção ou inculcação dos discursos presentes na obra, mas porque são informados sobre as vantagens de seguir os modelos propostos. Eles acreditam que esta é uma escolha pessoal e que as prescrições que constam das obras são o melhor caminho para a qualificação de suas práticas e o almejado reconhecimento profissional. 0 professor cursista é visto como sujeito de suas escolhas, pois a ele é atribuída a possibilidade de pensar que pode "livremente" definir os modos de desenvolver sua prática docente na educação infantil - apenas seguindo as orientações dos autores enquanto interlocutores e especialistas na temática em questão.

Como afirma Bocchetti (2008, p. 56), mais do que ensinar ao professor o que deve fazer, “importa também ensiná-lo a se enxergar de uma forma específica para que, com base na verdade apresentada, possa se regular constantemente". Desse modo, é possível dizer que tais efeitos do poder se tornam invisíveis e produtivos, potencialmente promotores de um processo permanente de autorregulação do 
professor em relação às suas ações na escola.

Dando sequência ao artigo, na próxima seção será apresentada a segunda seção analítica, cujo foco é a problematização dos discursos sobre aprendizagem que constam dos livros analisados.

\section{Aprendizagem: ludicidade, fetichismo da infância e imperativo do prazer}

Ao observar e agir sobre os objetos, a criança estabelece relações importantes para o conhecimento dos fenômenos que se apresentam no nosso cotidiano. No texto anterior, vimos que a humanidade começou a produzir conhecimento agindo, manipulando, observando e formulando questões. A criança não fica atrás. Ela também age sobre 0 mundo, o observa e formula questões. (Lopes; Mendes; Faria, 2006c, p. 44-45)

[...] as crianças aprendem de várias maneiras, participando de atividades que elas mesmas inventam e outras que as instituições promovem. Existem possibilidades de ola) professor(a) transformar a curiosidade das crianças em conhecimento no cotidiano das creches, pré-escolas e escolas, levando em consideração que a criança precisa experimentar o mundo. (Lopes; Mendes; Faria, 2006c, p. 45)

As crianças aprendem quando indagam e expressam sua curiosidade. 0 movimento é uma necessidade das crianças. As crianças precisam correr, tocar, explorar tudo o que as cerca. Com seus corpos e relações, as crianças vão apontando os caminhos necessários à elaboração dos projetos e dos conteúdos de ensino que vão compor nossos currículos. (Lopes; Mendes; Faria, 2006a, p. 30)

A participação das crianças nas atividades de exploração do mundo social tem grande importância. Você pode saber se uma atividade está sendo bem conduzida ou não só de ver o tipo de engajamento das crianças nas suas propostas. A criança, quando se envolve, cai de corpo e alma no que está fazendo. Quando não gosta, vira as costas. Essa é uma boa medida para avaliarmos se nossa proposta está tendo ou não significado para o grupo de crianças com as quais trabalhamos. (Lopes; Mendes; Faria, 2006d, p. 58)

Criança não aprende ficando quietinha, calando a boca e ouvindo o que falamos com ela. Criança aprende é mexendo, falando, perguntando, experimentando, usando seu corpo. Se a criança não está realmente empenhada no que faz, dificilmente estará aprendendo. (Lopes; Mendes; Faria, 2006d, p. 59)

Procure organizar a sala, o pátio, o corredor, enfim, os espaços que vocês irão ocupar de forma a contemplar as necessidades do seu grupo. Onde há espaço, há movimento. 0 movimento é sempre livre. 0 significado e o sentido que damos a ele é que o relaciona com uma razão, com uma história, um desejo, um encontro, um universo social e 
individual. (Lopes; Mendes; Faria, 2006a, p. 61)

0 objetivo das creches, pré-escolas e escolas que possuem turmas de educação infantil, no que tange às artes visuais, deve se estruturar na ideia de que as crianças possam aflorar em suas expressões, desenhando, pintando ou modelando, sem bloqueios, a partir de suas necessidades e desejos, acessando continuamente diferentes códigos estéticos de diferentes culturas - regionais, nacionais ou internacionais -, ampliando, assim, seu conhecimento do mundo e sua maneira de colocar-se neste mundo. Não se trata, então, de impor conteúdos e aprendizados, mas de oferecer experiências estéticas significativas que possam ser incorporadas e que venham ampliar seus repertórios visuais, contribuindo com sua formação cultural. (Lopes; Mendes; Faria, 2006b, p. 29)

Eis algumas lições sobre aprendizagem na educação infantil ensinadas no material didático do Prolnfantil: al as crianças aprendem participando de atividades que elas mesmas inventam e de outras que as instituições promovem; b) as crianças aprendem quando indagam e expressam as suas curiosidades; c) as crianças aprendem quando têm os seus interesses e as suas necessidades contemplados; d) as crianças aprendem falando, mexendo, perguntando, experimentando e usando o próprio corpo; el as crianças aprendem correndo, tocando e explorando tudo o que as rodeia. A compreensão de tais lições, com seus significados, que adquirem sentido através da leitura do professor e da correlata autoavaliação permanente de sua prática em sala de aula, possibilita problematizar a produção de verdades constantes nos discursos do material, vistos muitas vezes pelos docentes como sendo apenas criativos, inovadores, progressistas, neutros e atemporais.

A aprendizagem é uma tônica central do material analisado, sendo evidente a presença marcante, nos discursos dos livros, do enfoque cognitivista. Este é decorrente de uma pedagogia "centrada na criança", orientada a partir dos interesses delas, de suas necessidades e de seu desenvolvimento evolutivo (perspectiva orientada e regulada pelos postulados "científicos" da psicologia do desenvolvimento). Através das prescrições apresentadas, o professor em formação "capturado" pela leitura passa a entender a aprendizagem infantil a partir de uma lógica assentada em uma perspectiva cognitivista. Isso torna-se fundamental para a legitimação do programa e para a produção e a definição do perfil contemporâneo de profissional que atua na educação infantil.

A partir de tal perspectiva, o professor é visto como mediador, interlocutor, par mais experiente das crianças, que atua por meio da ludicidade. 0 lúdico passa a figurar como vetor principal da prática pedagógica na educação infantil, sendo significado em muitas passagens das obras em análise somente como sinônimo de prazer.

Arce (2004, p. 159), criticando tal posicionamento, argumenta que desse modo “a 
brincadeira passa a ser o escudo contra a falta de prazer que traz a escolarização e um antídoto ao assassinato da espontaneidade também causado por esta". Por essa razão, defende-se nas obras a ideia de que, através da proposição de seções lúdicas de aprendizagem, supostamente se rompe com a monotonia de atividades, dirigidas e planejadas pelo professor sem a participação efetiva das crianças. Efetua-se assim o que a referida autora denomina fetichismo da infância.

Por meio do rompimento das relações com o ensino e com o papel do professor enquanto transmissor de conhecimentos, coloca-se em funcionamento uma espécie de proteção ao universo infantil, que tem como objetivo o combate aos "efeitos nocivos" da escolarização. Para tanto, de acordo com Arce (2004), os professores passam a fetichizar a infância, como se ela fosse natural e espontaneamente detentora de conhecimento. Dessa forma, instaura-se o "imperativo do prazer infantil" como fundamento exclusivo da ação pedagógica e deixam-se em segundo plano os embates, os questionamentos, as mudanças de hipóteses e as frustrações decorrentes do processo de aprendizagem.

Assim, o imperativo do prazer infantil passa a ser visto como resultado exclusivo das ações desencadeadas pelo professor com o seu grupo de trabalho. A lição a ser aprendida é que o professor deve evitar a frustração das crianças e sempre planejar as suas propostas a partir dos interesses e das necessidades apresentados por elas.

Burman (1998) destaca que o par interesse/necessidade compõe a dupla de elementos fundamentais da pedagogia centrada na criança, que é efetivada, conforme os postulados considerados científicos, somente através do jogo e da descoberta. Para atuar desse modo, o professor deve aprender que existem etapas evolutivas a ser respeitadas e que a aprendizagem está diretamente relacionada com o desenvolvimento social e emocional das crianças. A aprendizagem deve partir sempre das escolhas individuais das crianças, pois são elas que devem fornecer ao professor a sequência e o conteúdo do processo de aprendizagem.

Conforme Sommer e Coutinho (2008, p. 26), essas são as bases para a operacionalização de práticas pedagógicas baseadas em uma perspectiva cognitivista. Essa perspectiva tem possibilitado, sem nenhuma reflexão crítica, o "deslocamento do eixo do ensino para o eixo da aprendizagem" e tem contribuído de modo indefectível para uma espécie de esvaziamento dos conteúdos, tanto nas escolas em que os professores atuam quanto nas universidades em que são formados. 0 professor é visto apenas como um mediador das relações estabelecidas entre as crianças e o conhecimento, e não mais como alguém que ensina. Vivencia-se uma espécie de epistemologia da prática no cotidiano das salas de aula de educação infantil.

De acordo com Sibilia (2012), a aprendizagem deixa de ser assegurada na 
transmissão de conhecimentos por parte do professor e passa a se apoiar nas operações que cada criança consegue realizar com as ferramentas de que dispõe. 0 sentido da aprendizagem desloca-se para o aprendiz, como uma figura que substitui a do antigo aluno.

Por essa razão, é recorrente o pressuposto de que a ação das crianças é fundamental para que a aprendizagem ocorra de modo satisfatório. 0 princípio da aprendizagem ativa é referendado em reflexões embasadas na psicologia, a respeito de como o trabalho educativo deve se organizar para atingir fins específicos. Ele passa assim a ocupar um lugar privilegiado na luta pela imposição de verdades que referendam práticas pedagógicas consideradas inovadoras e na correlata constituição dos professores que se encontram em processo de formação no programa.

O discurso da aprendizagem ativa constrói uma metodologia a partir do campo de possibilidades que coloca em funcionamento. 0 valor de verdade atribuído a tal enunciação torna o discurso da aprendizagem ativa uma prática efetiva - que deve (no sentido imperativo do termo) ser viabilizada por meio do trabalho do professor, não existindo outro modo eficaz para a efetivação de uma prática qualificada na educação infantil.

Esse discurso prescritivo atribui uma demanda ao campo educacional, fazendo que diversos mecanismos pedagógicos de "monitoramento" das ações desenvolvidas em sala de aula pelo cursista sejam operacionalizados lencontros quinzenais, relatos das atividades, avaliação das propostas desenvolvidas, observação da reação das crianças em relação às atividades, conversas com o tutor, etc.). Procura-se, desse modo, promover a operacionalização correta das propostas descritas nas obras.

Pelas razões expostas, a operacionalização de uma aprendizagem ativa é considerada o único meio de exercício da docência, tendo em vista o desenvolvimento integral das crianças. No decorrer das orientações constantes do material analisado, as propostas pedagógicas a ser postas em prática em sala de aula são descritas a partir de um discurso prescritivo que apresenta afirmações universais sobre o desenvolvimento infantil e que se pretende aplicado a diferentes contextos e situações sociais.

0 ensinamento fundamental dos discursos é a ideia de que a criança é a principal responsável pela construção de seu conhecimento. Através da ação constante proporcionada por experiências lúdicas mediadas pelo professor (que atendam a seus interesses e necessidades), ela aprenderá o que é previsto para o seu nível de desenvolvimento.

A promoção da aprendizagem a partir da ludicidade, do fetichismo da infância e do imperativo do prazer, apresentados no material do Programa, enuncia novos 
modos de pensar sobre a criança. A ludicidade apresenta-se como condição indispensável para que as propostas sejam realizadas em sala de aula, pois é vista como um contraponto às práticas entendidas como escolarizantes e centradas no ensino de conteúdos. Para isso, é necessário que o professor observe as reações das crianças, tendo em vista a satisfação de seus interesses e necessidades, por meio da transformação de suas curiosidades em conhecimentos.

A tríade apresentada constitui um roteiro de ação pedagógica, exigindo um modo específico de ser professor na educação infantil, no qual, segundo Bocchetti (2008, p. 51), existe um tipo “de elaboração pedagógica onde quase nada é ensinado (se por ensino entendemos qualquer modalidade de transmissão de conhecimentos), mas onde muitas coisas são, não obstante, aprendidas".

Prosseguindo a discussão, na próxima seção será apresentada a terceira seção analítica, cuja tônica são os discursos sobre formação docente veiculados nos livros analisados.

\section{Formação docente: autoavaliação, regulação e empreendedorismo}

O curso se propõe a contribuir para a formação de: um professor capaz de dar continuidade a seu próprio processo de aprendizagem, um cidadão responsável e participativo, integrado ao projeto da sociedade em que vive e, ao mesmo tempo, crítico e transformador. (Brasil, 2006, p. 26)

Nosso desejo é que neste curso do Prolnfantil você tenha descoberto e compartilhado muitas coisas com as crianças e com os(as) professores(as) que trabalham na sua creche, pré-escola ou escola. Esta etapa está terminando, mas você deve prosseguir estudando e buscando ampliar os horizontes da sua prática pedagógica, transformando antigos conhecimentos e procurando novos caminhos. E, se algum obstáculo surgir, como diz a música: tente outra vez. (Lopes; Mendes; Faria, 2006d, p. 66)

A prática pedagógica é algo que se recria a todo o momento em que dela participamos. Você, como professor(a), terá de reinventar suas práticas a partir das discussões com seus colegas e da leitura de livros que procuram inovar, uma vez que muitos de nós passamos por escolas arcaicas e tivemos um percurso escolar centrado no conteúdo, com pouco espaço para a descoberta, a construção do conhecimento e o contato com a diversidade da(s) cultura(s) que nos rodeia(m). (Lopes; Mendes; Faria, 2006d, p. 42) Observe que não estamos sugerindo uma organização do trabalho pedagógico como uma receita de bolo. Aliás, aposto que, quando você vai fazer um bolo, nunca segue passo a passo o que está escrito na receita, não é mesmo? Pode ser que você faça igualzinho ao que está na receita, até para ver se dá certo mesmo. Mas depois você começa a inovar, acrescentar um ingrediente que, a seu ver, pode incrementar o sabor 
daquele bolo. É assim também na nossa prática como professor(a). (Lopes; Mendes; Faria, 2006d, p. 42)

Estamos chegando ao final do curso! Você consegue perceber mudanças na sua prática? Como as leituras têm contribuído para a reflexão sobre o seu trabalho? Qual das unidades foi a que mais te envolveu? Escolha uma prática ou reflexão que passou a fazer parte de seu cotidiano a partir do estudo que estamos desenvolvendo. (Lopes; Mendes; Faria, 2006e, p. 69)

Autoavaliação, regulação profissional e empreendedorismo apresentam-se como os fundamentos da proposta de formação docente presente no material analisado. Esses elementos, ao ser enunciados nos discursos dos livros, objetivam a formação do que Bocchetti (2008, p. 117) intitula de formação de um professor mínimo, ou seja, um profissional que sabe, ao menos minimamente, “agir de acordo com os pressupostos dos discursos educacionais atuais que permeiam a formação de professores e que é capaz de se (auto)regular continuamente frente a tais referenciais".

O professor mínimo, conforme o autor, segue um modelo de atuação e reflexão voltado continuamente a uma verdade estabelecida. A partir dela, analisa permanentemente a si e a seus alunos, deixando em segundo plano os seus próprios modos de constituição docente (suas histórias de vida, leituras, experiências profissionais e reflexões a partir do contexto social em que atual. 0 professor mínimo é alguém que, atrelado aos seus referenciais iniciais de formação, busca a continuidade de sua aprendizagem. Segundo Ehrenberg (2010), ele aprende a se governar por si mesmo e a encontrar as orientações para sua existência, através de uma formação permanente.

A partir da leitura dos trechos selecionados e também dos discursos constantes das obras analisadas em seu conjunto, é possível perceber que os enunciados sobre formação docente que constam do material se aproximam da ordem do discurso empresarial. Esse discurso está fortemente atravessado por uma lógica concorrencial, que atribui ao próprio indivíduo a responsabilidade por sua atualização, pelo planejamento de seus investimentos educacionais e pela obtenção de êxito em suas escolhas profissionais.

Por esse motivo, pensando especificamente na formação do professor de educação infantil proposta pelo programa, é preciso destacar que esse profissional contemporaneamente precisa demonstrar, de forma constante, plasticidade, adaptabilidade e flexibilidade no exercício de diferentes funções e também na assunção dos riscos pelo sucesso ou fracasso dos seus próprios empreendimentos. Percebe-se, durante o decorrer das lições dos livros, que os professores passam a ser vistos como agentes econômicos que precisam valorizar e ampliar 
continuamente suas aptidões profissionais, no intuito de se tornarem competitivos no mercado de trabalho de uma sociedade eminentemente empresarial.

De modo semelhante ao que Arce (2001) demonstrou em sua pesquisa, é possível evidenciar que ao docente não é permitido permanecer da mesma forma por muito tempo. Ele deve se modernizar, incorporar conhecimentos que estejam sendo valorizados e seguir em frente, através do escrutínio minucioso de suas ações, verificando possíveis falhas e desenvolvendo sempre novas aptidões.

Cabe então ao professor administrar seus conhecimentos ao longo de sua vida, pois é preciso investir no aprimoramento de suas competências para não se tornar obsoleto. Tal aprimoramento é emergente das novas configurações, dos conceitos de educação e de profissão que se encaminham cada vez mais para uma perspectiva de controle e formação contínua dos indivíduos.

Nesse sentido, percebe-se a passagem do governamento dos outros para 0 governamento de si mesmo, no qual se atinge a subjetividade dos professores em formação por meio das obras, exercendo, de forma sutil, o controle e o monitoramento dos investimentos realizados por eles. Isso ocorre porque, em um mundo regido pela economia, cuja gestão é exercida pelo mercado, é necessário ativar novas práticas de governamento, que possibilitem ao indivíduo se perceber como alguém autônomo e livre para realizar as suas próprias escolhas. Eis a estratégia de governamento posta em funcionamento no que diz respeito ao processo de formação docente do Prolnfantil.

Por fim, a partir das análises apresentadas, na próxima seção serão encaminhadas as considerações finais do artigo.

\section{Considerações finais}

Através da análise das estratégias de governamento operacionalizadas por meio dos discursos presentes nos materiais, é possível perceber os livros do programa enquanto um conjunto de enunciados pertencentes ao campo discursivo da pedagogia. Eles, através de ensinamentos sobre aprendizagem infantil e formação docente, operam na tentativa de produzir certas conformações nas subjetividades dos professores.

Os ensinamentos do Prolnfantil encontram-se dentro de determinada ordem do discurso, na qual se articulam saber, poder e sujeição. Essa ordem discursiva possui um léxico pedagógico, metodologias e recomendações que têm o intuito de que o cursista se reconheça enquanto profissional que atua na educação infantil. Para tanto, os discursos presentes nos materiais prescrevem formas de educar as crianças no tempo presente, a partir de estratégias de governamento que visam à 
operacionalização de uma prática pedagógica fundamentada em uma perspectiva cognitivista de ensino.

As estratégias de governamento das subjetividades docentes desenvolvidas e legitimadas pelo Prolnfantil, por meio dos ensinamentos que constam dos livros, investem em nível discursivo na tentativa de direcionar as reflexões realizadas pelos cursistas. Desse modo, é perceptível o caráter autoinstrucional das leituras propostas no curso e a ênfase delas no processo de autoavaliação, regulação profissional e empreendedorismo docente.

Os discursos veiculados por meio dos materiais analisados não procuram apenas conferir forma às verdades pedagógicas por eles enunciadas sobre aprendizagem e formação docente. Eles objetivam principalmente a operacionalização de estratégias de governamento que garantam que tais verdades sejam apresentadas e continuamente confirmadas junto aos cursistas.

Isso ocorre porque os mecanismos de identificação utilizados no vocabulário empregado nos textos constantes do material são elaborados com base em “argumentos teóricos que estão em voga”, argumentos que já circulam e têm força de persuasão sobre os docentes, tais como: participação ativa das crianças nas atividades propostas, ênfase na aprendizagem e não no ensino, planejamento baseado nos interesses e nas necessidades das crianças, mediação do processo de aprendizagem, papel do professor como par mais experiente das crianças e o lúdico como vetor principal da prática pedagógica.

Desse modo, discursivamente, opera-se uma tentativa permanente de convencimento do cursista de que, através das lições apresentadas nos livros de estudo, caso sejam devidamente executadas em sala de aula, seu sucesso e reconhecimento como professor de educação infantil serão garantidos.

\section{Referências}

ARCE, Alessandra. Compre o kit neoliberal para Educação Infantil e ganhe grátis os dez passos para se tornar um professor reflexivo. Educação e Sociedade, Campinas, v. 23, n. 74, p. 251-283, abr. 2001.

. Pedagogia da Infância ou fetichismo da infância? In: DUARTE, Newton

(Org.). Crítica ao fetichismo da individualidade. Campinas: Autores Associados, 2004. p. 146-168.

BARBOSA, Ivone Garcia. 0 Prolnfantil e a formação do professor. Revista Retratos da Escola, Brasília, v. 5, n. 39, p. 285-399, jul./dez. 2011.

BOCCHETTI, André. Por um professor mínimo: a produção “à distância” do sujeito docente. 2008. 199f. Dissertação (Mestrado em Educação)- Programa de Pós- 
Graduação em Educação, Faculdade de Educação, Universidade de São Paulo, 2008.

BOCCHETTI, André; BUENO, Belmira Oliveira. Um professor (sempre) a formar: - governo das subjetividades docentes em programas especiais de formação. Currículo sem Fronteiras, [S.l.], v. 12, n. 2, p. 376-392, maio/ago. 2012.

BRASIL, MEC/SEB/SEED. PROINFANTIL: Programa de Formação Inicial de Professores de Educação Infantil: guia geral. Brasília: MEC/SEB/SEED, 2005. (Coleção Prolnfantil)

BURMAN, Érica. La desconstrucción de la psicologia evolutiva. Madrid: Visor, 1998. EHRENBERG, Alain. O culto da performance: da aventura empreendedora à depressão nervosa. Aparecida, SP: Ideias e Letras, 2010.

FOUCAULT, Michel. A arqueologia do saber. Rio de Janeiro: Forense Universitária, 2007.

. A ordem do discurso. São Paulo: Loyola, 2005.

Microfísica do poder. Rio de Janeiro, Edições Graal, 1987.

Segurança, território e população. São Paulo: Martins Fontes, 2008.

LOPES, Karina Rizek; MENDES, Roseane Pereira; FARIA Vitória Libia Barreto de (Org.). Livro de estudo: Módulo IV. Brasília: MEC/SEB/Seed, 2006a. (Coleção Prolnfantil; Unidade 4).

. Livro de estudo: Módulo IV. Brasília: MEC/SEB/Seed, 2006b. IColeção Prolnfantil; Unidade 5).

. Livro de estudo: Módulo IV. Brasília: MEC/SEB/Seed, 2006c. IColeção Prolnfantil; Unidade 6).

. Livro de estudo: Módulo IV. Brasília: MEC/SEB/Seed, 2006d. (Coleção Prolnfantil; Unidade 7).

. Livro de estudo: Módulo IV. Brasília: MEC/SEB/Seed, 2006e. (Coleção Prolnfantil; Unidade 8).

PALAMIDESSI, Mariano Ismael. La producción del "maestro constructivista" en el discurso curricular. Educação e Realidade, Porto Alegre, v. 21, n. 2, p. 191-213, jul./ dez.1996.

SIBILIA, Paula. Redes ou paredes: a escola em tempos de dispersão. Rio de Janeiro: Contraponto, 2012.

SOMMER, Luís Henrique; COUTINHO, Karyne Dias. Formação docente para um currículo inclusivo: armadilhas da linguagem. In: BONIN, lara Tatiana et al. (Org.). Cultura, identidade e formação de professores: perspectivas para escola contemporânea. Canoas: Ulbra, 2008. p. 17-32.

VEIGA-NETO, Alfredo. Educação e governamentalidade neoliberal: novos dispositivos, novas subjetividades. In: BRANCO, Guilherme Castelo; PORTOCARRERO, Vera. (Orgs.). Retratos de Foucault. Rio de Janeiro: Nau, 2000. p. 179-217.Recebido em junho de 2013 
Aprovado em dezembro de 2013

Rodrigo Saballa de Carvalho é doutor em Educação (UFRGS) e professor adjunto do Curso de Pedagogia da Universidade Federal da Fronteira Sul (UFFS, Erechim - RS). Realizou estágio de pós-doutorado em educação na Universidade Federal de Pelotas (UFPEL). E-mail: rsaballaAterra.com.br. 